\title{
Procedure for measuring the solar reflectance of flat or curved roofing assemblies
}

\author{
Hashem Akbari ${ }^{*}$ and Ronnen Levinson \\ Heat Island Group \\ Lawrence Berkeley National Laboratory \\ Berkeley, CA 94720 \\ and \\ Stephanie Stern \\ Cool Roof Rating Council \\ Oakland, CA 94612
}

\section{Abstract}

The widely used methods to measure the solar reflectance of roofing materials include ASTM standards E903 (spectrometer), C1549 (reflectometer), and E1918 (pyranometer). Standard E903 uses a spectrometer with an integrating sphere to measure the solar spectral reflectance of an area approximately $0.1 \mathrm{~cm}^{2}$. The solar spectral reflectance is then weighted with a solar spectral irradiance to calculate the solar reflectance. Standard C1549 uses a reflectometer to measure the solar reflectance of an area approximately $5 \mathrm{~cm}^{2}$. Both E903 and C1549 are best suited to measurement of the solar reflectance of flat, homogeneous surfaces. Standard E1918 uses a pyranometer to measure the solar reflectance of an area approximately $10 \mathrm{~m}^{2}$, and is best applied to large surfaces that may also be rough and/or nonuniform.

We describe a technique that uses a pyranometer to measure the solar reflectance of a uniform or variegated sample with an area of approximately $1 \mathrm{~m}^{2}$, and use this technique (referred to as E1918A) to measure the solar reflectance of low- and high-profile tile assemblies. For 10 large $\left(10 \mathrm{~m}^{2}\right)$ tile assemblies whose E1918 solar reflectances ranged from 0.10 to 0.50, the magnitude of the difference between the E1918A and E1918 measurements did not exceed 0.02 for unicolor assemblies, and did not exceed 0.03 for multicolor assemblies.

Keywords: cool roofs, solar reflectance, roof tiles, pyranometer, albedometer, solar spectrum reflectometer, spectrometer, albedo, E1918

\footnotetext{
${ }^{*}$ Corresponding author. Email: $\underline{\text { H_Akbari@LBL.gov. Tel: +1-510-486-4287 }}$
} 


\section{Introduction}

Roofs that have high solar reflectance (high ability to reflect sunlight) and high thermal emittance (high ability to radiate heat) tend to stay cool in the sun. Substituting a cool roof for a noncool roof can decrease cooling-electricity use, cooling-power demand, and required capacity of cooling equipment. Cool roofs may slightly increase heating-energy consumption. By reducing heat flow from the roof's surface to the outside air, widespread installation of cool roofs can also lower the outside air temperature, slowing ozone formation and increasing human comfort in summer (Akbari et al. 2001).

Many monitoring studies in California and Florida have demonstrated that increasing roof solar reflectance to 0.60 from the range of 0.10 to 0.20 results in building cooling-energy savings in excess of 20\% (Akbari et al. 2005; Akbari 2003; Akbari et al. 2001; Akbari et al. 1997; Konopacki and Akbari 2001; Parker et al. 1998; Parker et al. 1995). Konopacki et al. (1997) estimate that the U.S. could save more than $\$ 750$ million $(\mathrm{M})$ per year in net energy expenditure (cooling-energy cost savings minus heating-energy cost penalties). These cost savings account for only the direct effect of cool roofs, and would double once the values of indirect energy savings and smog reduction from cooling of the ambient air are included (Akbari et al. 2001).

To take advantage of these potential savings in energy and peak-demand, many institutions have developed codes and standards for implementing cool roofs. For example, ASHRAE standards 90.1-2004 (new commercial buildings) and 90.2-2007 (new residential buildings) offer credits for installing roofs with high solar reflectance (ASHRAE 2004, 2007). California's current (year 2005) “Title 24" building energy efficiency standards prescribe a minimum initial solar reflectance of 0.70 and a minimum initial thermal emittance of 0.75 for low-sloped roofs on nonresidential buildings, with somewhat lower thermal emittance requirements for roofs of especially high solar reflectance. The current Title 24 standards also offer performance credits for the use of cool products on other types of roofs (CEC 2005). The California Energy Commission is currently considering the addition to Title 24 of prescriptive requirements for the minimum solar reflectance and minimum thermal emittance for steep- and low-sloped roofs on residential buildings, as well as for steep-sloped roofs on nonresidential buildings (Akbari et al. 2007; Wray et al. 2007).

California's Title 24 requires that the solar reflectance and thermal emittance of roofing products be rated by the Cool Roof Rating Council (CRRC). The CRRC currently accepts solar reflectances measured by via ASTM standards E903 (spectrometer), C1549 (reflectometer), and/or E1918 (pyranometer). ASTM E903: Standard test method for solar absorptance, reflectance, and transmittance of materials using integrating spheres (ASTM 1996) uses a spectrometer with an integrating sphere to measure the solar spectral reflectance of an area approximately $0.1 \mathrm{~cm}^{2}$. The solar spectral reflectance is then weighted with a solar spectral irradiance to calculate solar reflectance. ASTM C1549: Standard test method for determination of solar reflectance near ambient temperature using a portable solar reflectometer (ASTM 2002) uses a reflectometer to measure the solar reflectance of an area approximately $5 \mathrm{~cm}^{2}$. E903 and C1549 are each best applied to flat and homogenous surfaces. ASTM E1918: Standard test method for measuring solar reflectance of horizontal and low-sloped surfaces in the field (ASTM 1997) uses a pyranometer to measure the solar reflectance of a $10 \mathrm{~m}^{2}$ area, and is best applied to large surfaces that may also be rough and/or non-uniform.

Measuring the solar reflectance of a heterogenous flat surface (or quasi-flat surface, such as that of a fiberglass asphalt shingle) requires variations to those techniques applied to a uniform flat surface. In an earlier study, we developed a statistical sampling method ("C1549MC") to measure the solar reflectance of a variegated and approximately flat surface via repeated application of ASTM standard C1549 (CRRC 2007). C1549MC, also called CRRC-1 Test Method\#1, was adopted by the CRRC for the measurement of the solar reflectance of fiberglass asphalt shingles and other flat (or quasi-flat) variegated samples. 
The solar reflectance of a high-profile (curved) tile assembly cannot be accurately measured with C1549MC because (a) a reflectometer is not well-suited to measuring the reflectance of a curved surface; and (b) light reflected from a curved tile may be absorbed by a neighboring tile, decreasing the reflectance of the assembly. It is also difficult to replicate the same blend of colors contained in a full tile assembly when taking spot measurements with a reflectometer.

E1918 may be used if the target is at least $10 \mathrm{~m}^{2}$ in area and roughly square or circular in shape. The difficulty of transporting such large samples for the natural-exposure weathering required by the CRRC makes the sample-size requirements of E1918 costly and inconvenient.

This study describes the development of "E1918A," a variation on E1918, which uses a pyranometer and a pair of black and white masks to measure the solar reflectance of a surface as small as $1 \mathrm{~m}^{2}$ (Appendix A). This permits the measurement of the solar reflectance of samples whose areas are less than the $10 \mathrm{~m}^{2}$ required by E1918, such as prototype shingle panels and tile assemblies.

The objective of this study is to validate the application of E1918A for measuring the solar reflectance of high- and low-profile clay and concrete tile assemblies. We expect the results will apply equally to other flat and non-flat roofing materials, including fiberglass asphalt shingles, wood shakes, and tile-shaped metal products.

\section{E1918A Theory}

Consider a target surface (denoted "t") of area $A_{\mathrm{t}}$ and solar reflectance $R_{\mathrm{t}}$ whose surroundings ("s") have solar reflectance $R_{\mathrm{s}}$. Both the target and its surroundings are illuminated by sunlight of horizontal irradiance (power per unit area) $I_{\mathrm{H}}$. We measure the reflected solar irradiance $I$ incident on the sensor of a horizontal, downward-facing pyranometer when (1) the target is exactly covered by a solar-opaque white mask of known (ASTM E903) solar reflectance $R_{\mathrm{w}}$; (2) the target is exactly covered by a solar-opaque black mask of known solar reflectance $R_{\mathrm{b}}$; and (3) the target is uncovered. The irradiances $I_{1}, I_{2}$, and $I_{3}$ are related to the horizontal solar irradiance $I_{\mathrm{H}}$ and the solar reflectances $R_{\mathrm{t}}, R_{\mathrm{S}}, R_{\mathrm{w}}$, and $R_{\mathrm{b}}$ by

$$
\begin{aligned}
& I_{1}=\left[F R_{\mathrm{w}}+(1-F) R_{s}\right] I_{\mathrm{H}} \\
& I_{2}=\left[F R_{\mathrm{b}}+(1-F) R_{s}\right] I_{\mathrm{H}}
\end{aligned}
$$

and

$$
I_{3}=\left[F R_{\mathrm{t}}+(1-F) R_{s}\right] I_{\mathrm{H}}
$$

where $F$ is the view factor (a.k.a. shape factor, configuration factor, or radiation factor) from the pyranometer sensor to the target. Solving for the solar reflectance of the target yields

$$
R_{\mathrm{t}}=R_{\mathrm{b}}+\frac{I_{3}-I_{2}}{I_{1}-I_{2}}\left(R_{w}-R_{\mathrm{b}}\right)
$$

The error in measurement of reflected irradiance $I$ is inversely correlated to the view factor $F$; hence, the smaller $A_{\mathrm{t}}$, the larger the measurement error. In our experiments, we use a target area of approximately 1 $\mathrm{m}^{2}$. The measurement procedure is detailed in Appendix A. 


\section{Experiment Design}

We measured the solar reflectances of 14 clay and concrete tiles assemblies (Figure 1) via E1918 and E1918A, and measured the solar reflectance of nominally representative tile chips (Figure 2) via E903 ${ }^{\dagger}$. All measurements were performed under the conditions prescribed by E1918. The E1918 and E1918A measurements were performed on a clear sunny day with no clouds and no haze (August 9, 2006, 10 am 4pm PDT) in Lathrop, CA (37.82N, 121.29W). The measurement procedure is detailed in Appendix A. Each reported value of E1918 or E1918A solar reflectance is an average of three consecutive measurements at the approximate center of the assembly.

Ten of the assemblies were squares about $3.3 \mathrm{~m}(10 \mathrm{ft})$ on a side (area of $10 \mathrm{~m}^{2}$ ), and are termed "large"; the remaining four assemblies were squares about $2 \mathrm{~m}(6 \mathrm{ft})$ on a side, and are termed "small" (see Table 1). The 14 tile assemblies included

- $\quad$ one unicolor assembly of flat tiles (CRRC01);

- 4 multicolor assemblies of flat tiles, each composed of either multicolor tiles or a mix of monocolor tiles (CRRC02, CRRC07, CRRC08, CRRC09);

- 3 unicolor assemblies of curved tiles (CRRC03, CRRC05, CRRC06); and

- 6 multicolor assemblies of curved tiles, each composed of either multicolor tiles or a mix of unicolor tiles (CRRC04, CRRC10, CRRC11, CRRC12, CRRC13, CRRC14).

Five months later, we received small $(5 \mathrm{~cm} \times 5 \mathrm{~cm})$ tile chips (Figure 2) that manufacturers supplied from tiles nominally similar to those used to build the 14 assemblies shown in Figure 1. Some of these tile chips visually differed from the tiles used on in the assemblies, as described in Table 1 . Since we received multiple tile chips for each assembly, each tile chip is labeled with the number (01-14) of the assembly that it represents, followed by a unique letter $(\mathrm{a}, \mathrm{b}, \mathrm{c} . .$.$) . We measured the E903 air-mass-1.5 solar$ reflectance at the center of each chip.

\footnotetext{
${ }^{\dagger}$ The solar reflectances of the tile chips were also measured via ASTM C1549. However, we omit the C1549 values from the current report pending resolution of a systematic difference between C1549 and E903 measurements of the solar reflectance of "cool colored" surfaces-i.e., those whose near-infrared reflectances differ strongly from their visible reflectances. We will compare the C1549, E903, E1918, and/or E1918A solar reflectances of a variety of samples in a later study.
} 

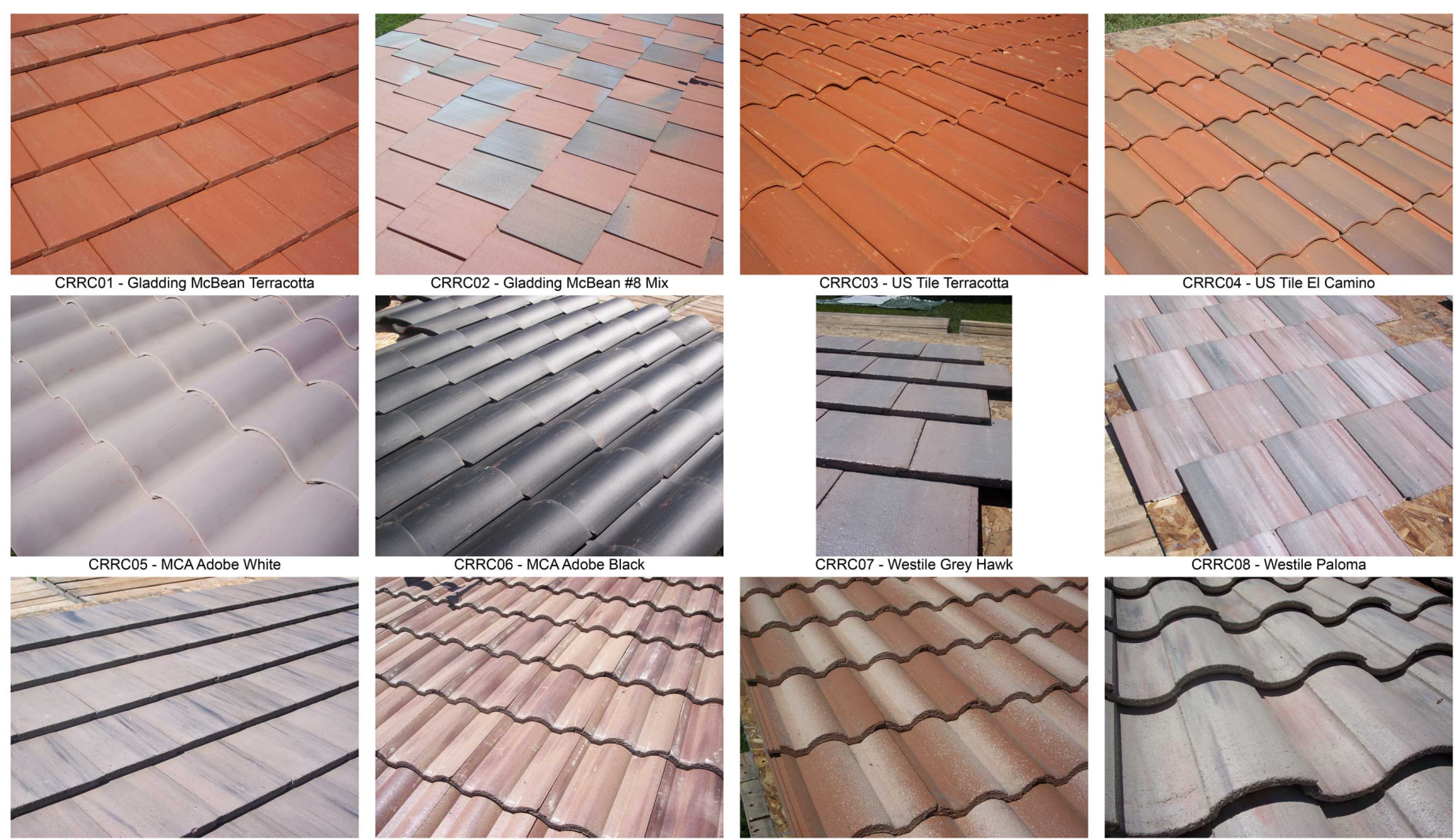

CRRC09 - MonierLifetile Desert Sage
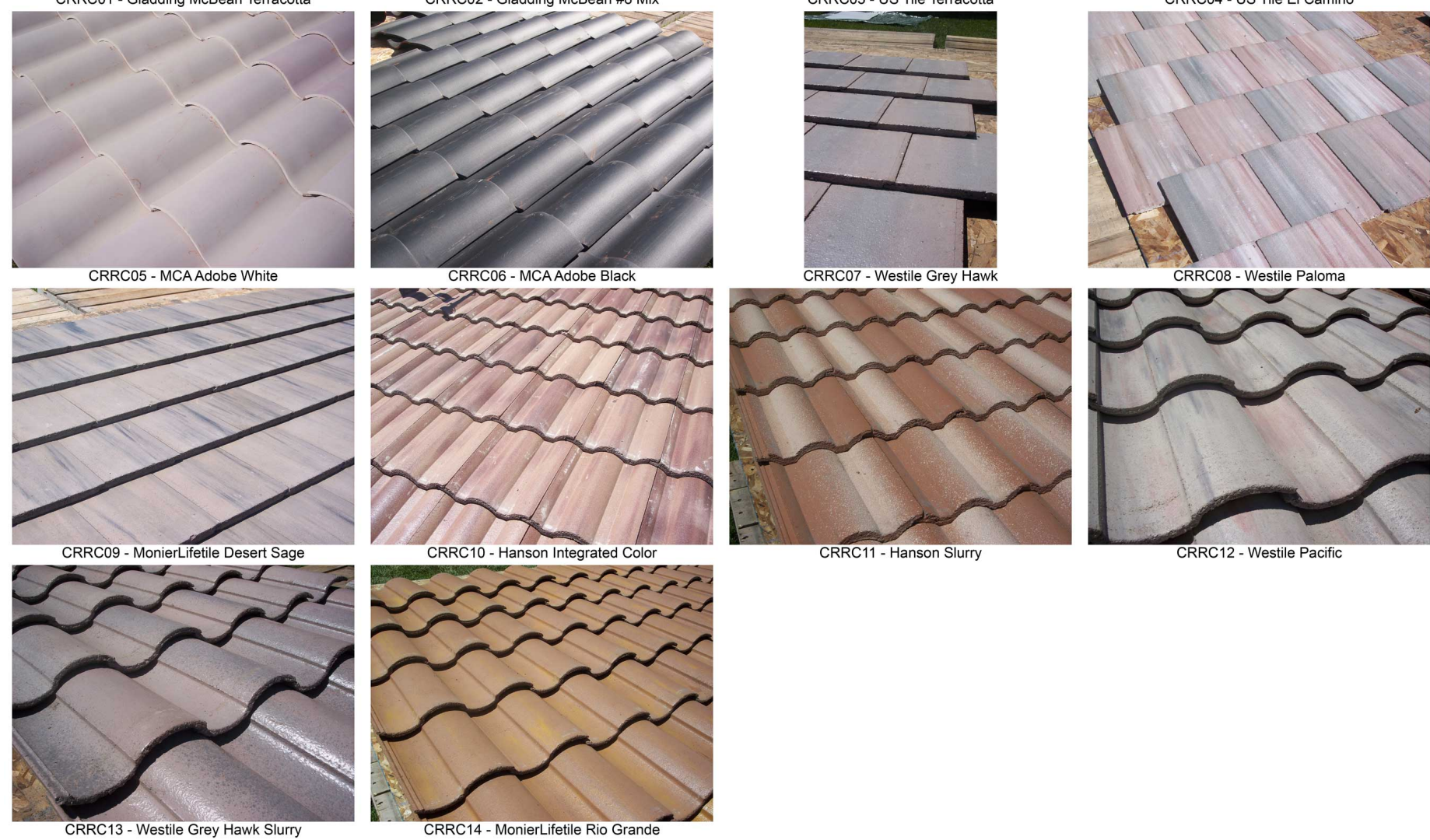

CRRC11 - Hanson Slurry

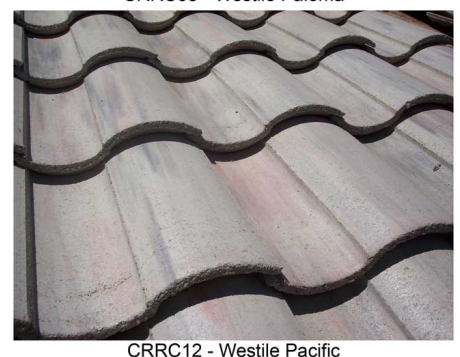

CRRC12 - Westile Pacific

Figure 1. Partial images of the 14 tile assemblies. The footprint of each assembly was either about $3.3 \mathrm{~m} \times 3.3 \mathrm{~m}$ (large samples) or about $2 \mathrm{~m} \times 2 \mathrm{~m}$ (small samples); see Table 1. 

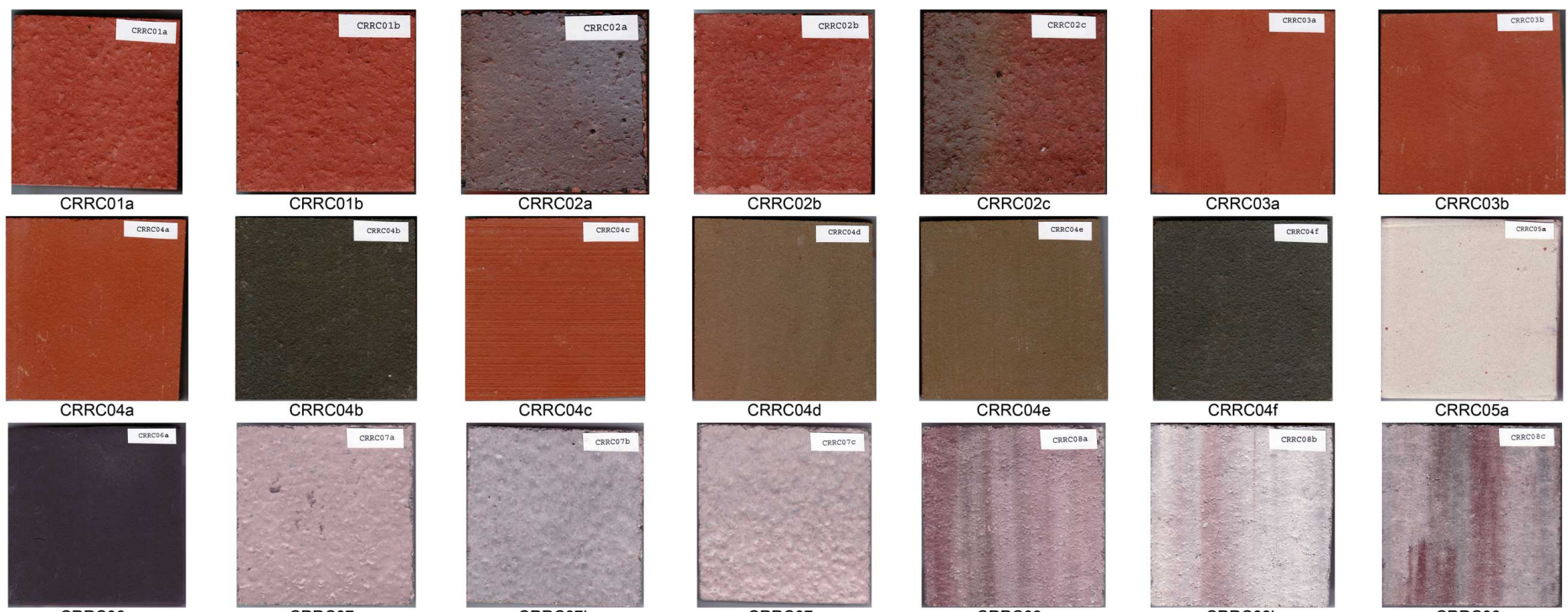

CRRC06
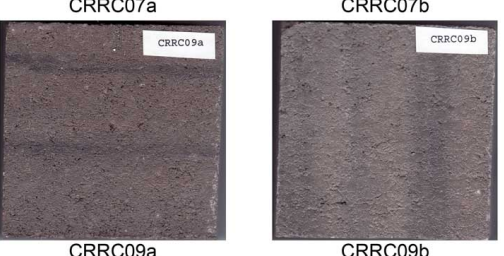

CRRC07c

CRRC08a
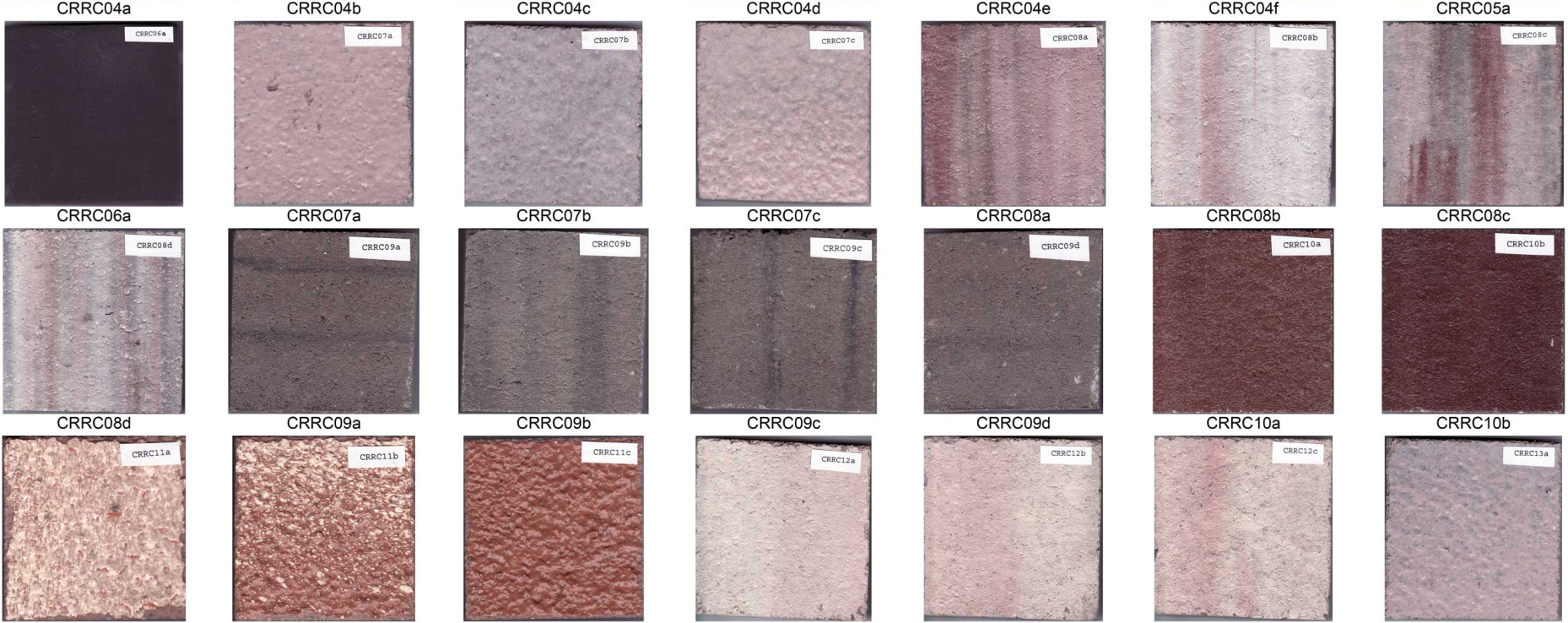

CRRC09b

CRRC09c

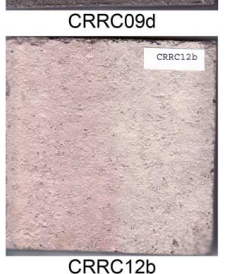

CRRC10a

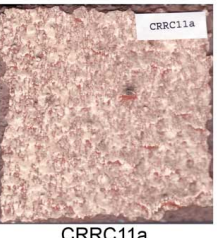

CRRC11a
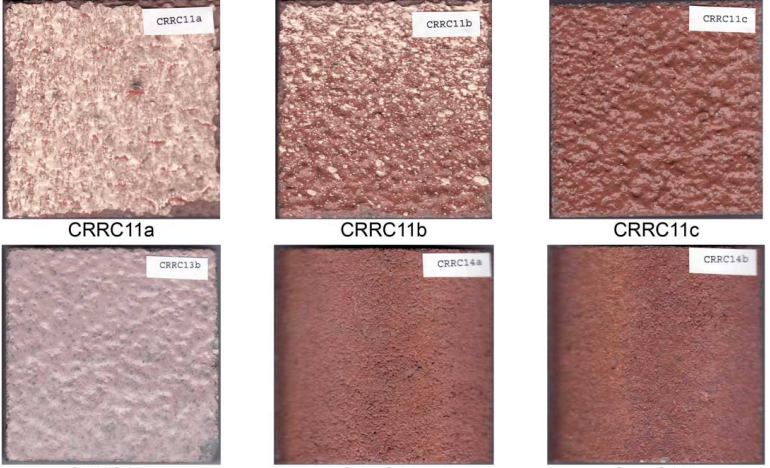

CRRC14b
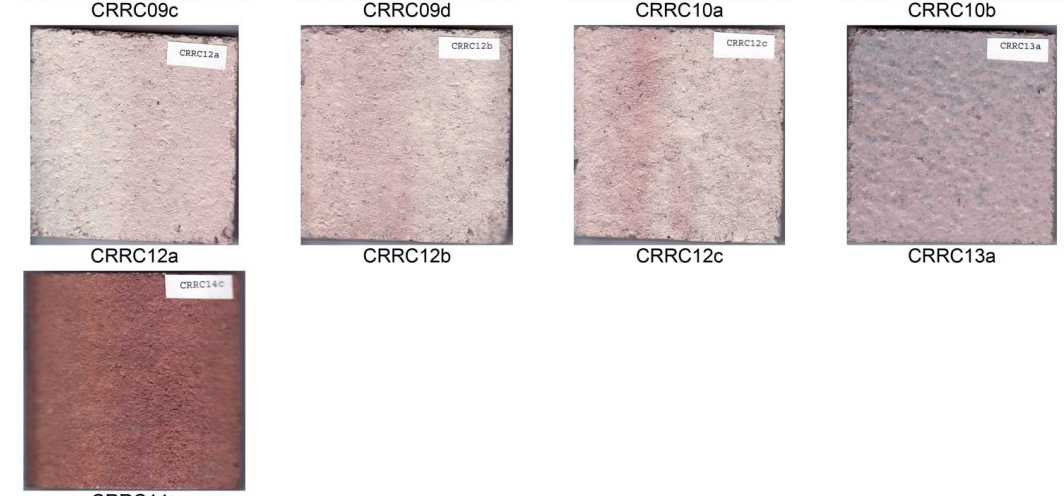

Figure 2. Images of the tile chips, each about $5 \mathrm{~cm} \times 5 \mathrm{~cm}$. Chip CRRCNNi is nominally representative of tile assembly CRRCNN. 


\section{Results}

\subsection{Comparison of E1918A and E1918 solar reflectances of large tile assemblies}

Figure 3 compares the E1918 and E1918A solar reflectances of the 10 large assemblies. For the six unicolor large assemblies, the absolute value of the difference in solar reflectance measurements (E1918A - E1918) does not exceed 0.02 (mean difference 0.01; RMS difference 0.01). For the four multicolor large assemblies, the absolute value of the difference does not exceed 0.03 (mean difference 0.00; RMS difference 0.02). The multicolor assemblies tend to exhibit a greater difference between E1918 and E1918A reflectance because the color blend in the smaller $\left(1 \mathrm{~m}^{2}\right)$ area sampled by E1918A was not necessarily identical to that in the larger $\left(10 \mathrm{~m}^{2}\right)$ area sampled by E1918.

The close agreement between the E1918 and E1918A solar reflectance measurements for large assemblies (within 0.02 for unicolor and 0.03 for multicolor) demonstrates that E1918A can be used in place of E1918 to measure the solar reflectance of samples as small as $1 \mathrm{~m}^{2}\left(\right.$ about $\left.10 \mathrm{ft}^{2}\right)$.

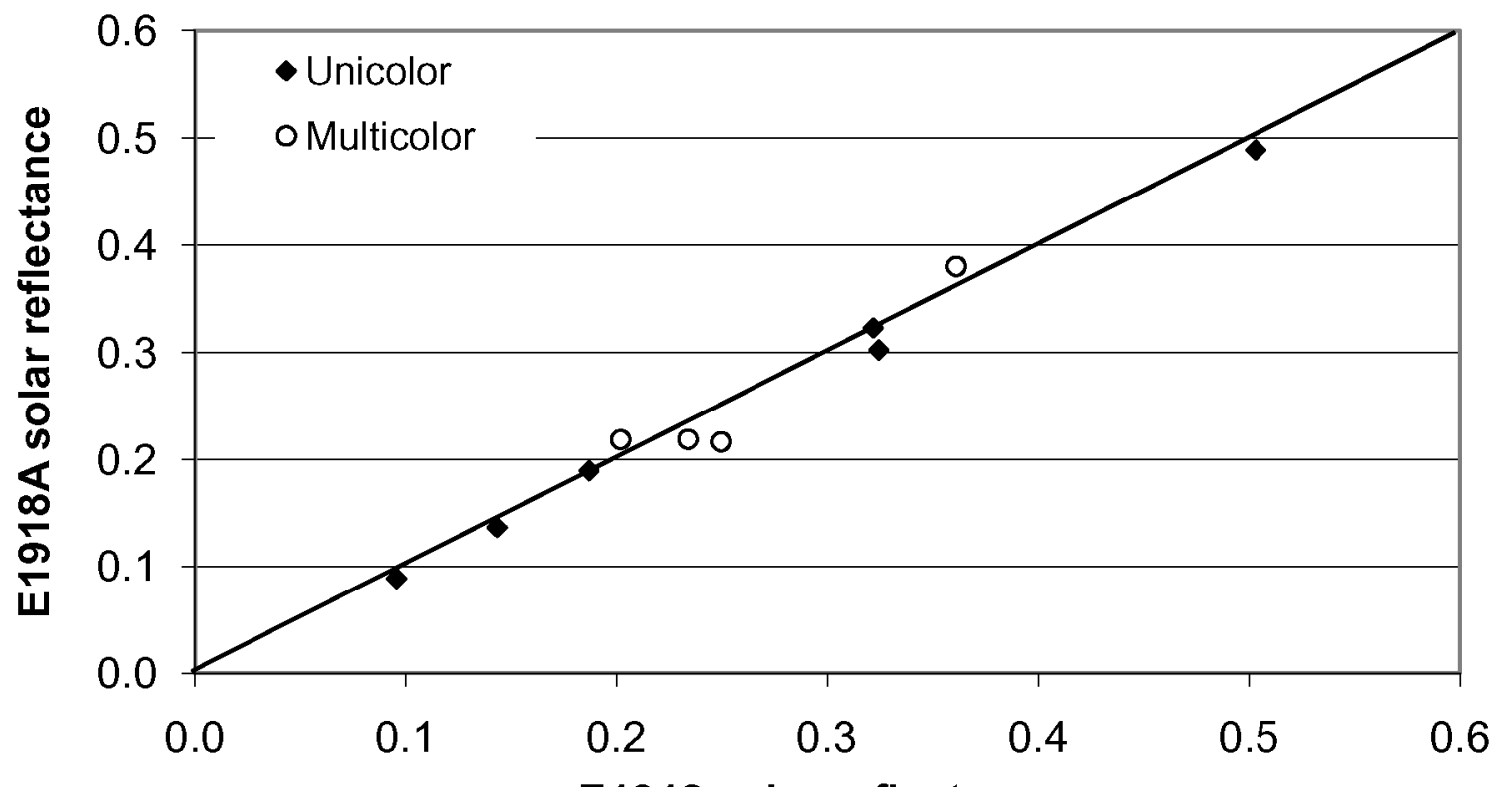

E1918 solar reflectance
Figure 3. Comparison of the E1918 and E1918A solar reflectances of six unicolor and four multicolor large tile assemblies.

\subsection{Comparison of E1918A tile-assembly solar reflectances to E903 tile-chip solar reflectances}

We measured the solar reflectance of each tile chip via E903 (spectrometer). When we compared the colors of the tile chips to those of the assembly tiles, we identified seven instances in which the color of the chip varied slightly from that of the assembly tile, and three instances in which the color of the chip varied noticeably from that of the assembly tile (see Table 1).

Table 1 compares the E1918A solar reflectances of the tile assemblies to the E903 solar reflectances of the nominally representative tile chips. The solar reflectance of unicolor flat terra-cotta tile assembly 
CRRC01 (0.32) is lower than those of its component tile chips (0.35-0.37). We are not certain whether this difference results from the assembly geometry or from variations in tile manufacture.

The solar reflectances of single-color curved assemblies CRRC03, CRRC05, and CRRC06 are 0.01, 0.06, and 0.01 lower than those of their respective chips. Our preliminary analysis of reflectance from curved surfaces suggests that tile-to-tile reflection and subsequent absorption of light can explain such differences (Berdahl et al. 2007). More research is needed to develop a method to estimate the solar reflectance of a tile assembly from that of its component tiles.

\section{Discussion}

For unicolor large assemblies, the solar reflectances measured by E1918 and E1918A differed by less than 0.02 (RMS difference 0.01). For multicolor large assemblies, the maximum absolute difference between the two measurements was about 0.03 (RMS difference 0.02 ). The greater variations between E1918 and E1918A observed for multicolor assemblies may indicate that the $1 \mathrm{~m}^{2}$ area of a multicolor assembly sampled by E1918A was not always representative of the entire $10 \mathrm{~m}^{2}$ assembly measured by E1918. The close agreement between the E1918 and E1918A solar reflectance measurements for large assemblies (within 0.03) demonstrates that E1918A can be used in place of E1918 to measure the solar reflectance of samples as small as $1 \mathrm{~m}^{2}$.

Many of the flat tile chips were needed for E903 measurements were not cut from the assembly tiles used in the E1918 and E1918A trials. This introduces some uncertainty in our comparison of the E918A solar reflectance of each tile assembly to the E903 solar reflectances of its nominally representative tile chips.

We estimate that tile-to-tile reflection and absorption may make the solar reflectance of a unicolor curved tile assembly about $10-15 \%$ lower than that of a truly representative flat tile chip. That is, if a unicolor flat tile chip has a solar reflectance of 0.50 , the solar reflectance of an assembly of curved tiles made of the same material may be only 0.42 to 0.45 (Berdahl et al. 2007). Further analysis of tile-to-tile multiple reflection and absorption is needed to estimate the reflectance of a tile assembly from the reflectances of representative tile chips.

This study compared E1918A solar reflectance measurements for low- and high-profile clay and concrete tile assemblies to those made by E1918. It validated E1918A by showing that in the absence of sampling errors (e.g., those experienced with multicolor tile assemblies), E1918A values agreed with CRRCapproved E1918 values to within 0.02. Since the solar reflectance of a roof assembly is primarily of function of the reflectance of the component roofing materials and the geometry of the assembly, we expect these results will equally apply to other similar high-profile roofing materials such as wood shakes or shaped metal products.

We also compared solar reflectance measurements using E1918A and E1918 and validated E1918A by showing that it agreed with E1918 (CRRC accepted method) to within difference 0.02, for low- and highprofile clay and concrete tile assemblies.

\section{Conclusion}

A pyranometer-based method of measuring solar reflectance ("E1918A") was designed to characterize the solar reflectance of an approximately $1 \mathrm{~m}^{2}$ surface. The surface can be uniform, variegated, flat, or curved. For 10 large $\left(10 \mathrm{~m}^{2}\right)$ tile assemblies ranging in solar reflectance from 0.10 to 0.50 , the agreement between the E1918A and E1918 measurements for unicolor assemblies was within 0.02, while that for multicolor assemblies was within 0.03. We conclude that E1918A can serve as an alternative to E1918 for measurement of the solar reflectance of low- and high-profile tile assemblies. Since the solar reflectance of a roof assembly is primarily of function of the reflectance of the component roofing materials and the 
geometry of the assembly, we expect these results will equally apply to other similar high-profile roofing materials such as wood shakes or shaped metal products.

\section{Acknowledgement}

This work was sponsored by a grant from the California Energy Commission Public Interest in Energy Research program (LB06002187) through the Assistant Secretary for Energy Efficiency and Renewable Energy under Contract No. DE-AC02-05CH11231. We would like to thank Rick Olson of the Tile Roofing Institute for coordinating the donation of the samples used in this study, and Jerry Vandewater of MonierLifetile for coordinating the outdoor measurements. We would also like to thank Gladding McBean Tile, Hanson Roof Tile, MCA Clay Tile, MonierLifetile, and US Tile for providing the samples.

\section{References}

Akbari, H., Wray, T., Levinson, R., Xu, T., 2007. Inclusion of solar reflectance and thermal emittance prescriptive requirements for steep-sloped nonresidential roofs in Title 24. Lawrence Berkeley National Laboratory Report LBNL-60331 (draft), Berkeley, CA. Online at http://energy.ca.gov/title24/2008standards/documents/2006-05-18 workshop/2006-05-19 NONRESDNTL STEEPSLOPED_COOL_ROOFS.PDF

Akbari, H., Levinson, R.M., Rainer, L., 2005. Monitoring the energy-use effects of cool roofs on California commercial buildings. Energy and Buildings 37(10), 1007-1016.

Akbari, H., 2003. Measured energy savings from the application of reflective roofs in two small nonresidential buildings. Energy 28, 953-967.

Akbari, H., Pomerantz, M., Taha, H., 2001. Cool surfaces and shade trees to reduce energy use and improve air quality in urban areas. Solar Energy 70(3), 295-310.

Akbari, H., Bretz, S., Taha, H., Kurn, D., Hanford, J., 1997. Peak power and cooling energy savings of high-albedo roofs. Energy and Buildings 25(2), 117-126.

ASHRAE. 2004. ASHRAE Standard 90.1-2004: Energy Standard for Buildings Except Low-Rise Residential Buildings. American Society of Heating, Refrigerating, and Air-Conditioning Engineers, Atlanta, GA.

ASHRAE. 2007. ASHRAE Standard 90.2-2007: Energy-Efficient Design of Low-Rise Residential Buildings. American Society of Heating, Refrigerating, and Air-Conditioning Engineers, Atlanta, GA.

ASTM. 1996. ASTM E 903-96: Standard test method for solar absorptance, reflectance, and transmittance of materials using integrating spheres. American Society for Testing and Materials. West Conshohocken, PA.

ASTM. 1997. ASTM E 1918-97: Standard test method for measuring solar reflectance of horizontal and low-sloped surfaces in the field. American Society for Testing and Materials. West Conshohocken, PA.

ASTM. 2002. ASTM C 1549-02: Standard test method for determination of solar reflectance near ambient temperature using a portable solar reflectometer. American Society for Testing and Materials. West Conshohocken, PA.

Berdahl, P., Akbari, H., Jacobs, J., Klink, F., 2007. Surface roughness effects on the solar reflectance of cool asphalt shingles. Lawrence Berkeley National Laboratory Report LBNL-62322, Berkeley, CA.

CEC. 2005. 2005 Building Energy Efficiency Standards for Residential and Nonresidential Buildings. CEC-400-2006-015. California Energy Commission, Sacramento, CA.

CRRC. 2007. CRRC-1 Method \#1: Standard practice for measuring solar reflectance of a flat, opaque, and heterogeneous surface using a portable solar reflectometer. Cool Roof Rating Council. Online at http://coolroofs.org/documents/CRRCTestMethod1Final072605.pdf 
Konopacki, S., Akbari, H., 2001. Measured energy savings and demand reduction from a reflective roof membrane on a large retail store in Austin. Lawrence Berkeley National Laboratory Report LBL47149, Berkeley, CA.

Konopacki, S., Akbari, H., Gabersek, S., Pomerantz, M., Gartland, L., 1997. Cooling energy saving potentials of light-colored roofs for residential and commercial buildings in 11 U.S. metropolitan areas. Lawrence Berkeley National Laboratory Report LBNL-39433, Berkeley, CA.

Parker, D.S., Sherwin, J.R., Sonne, J.K., 1998. Measured performance of reflective roofing systems in a florida commercial buildings. ASHRAE Transactions 104(1), American Society of Heating, Refrigeration, and Air Conditioning Engineers, Atlanta, Georgia, (January).

Parker, D. S., Barkaszi, Jr., S.F., Chandra, S., Beal, D.J., 1995. Measured cooling energy savings from reflective roofing systems in Florida: Field and laboratory research results. Proceeding of the Thermal Performance of the Exterior Envelopes of Buildings VI, December 4-8, 1995, Clearwater, FL.

Wray, C., Akbari, H., Levinson, R., Xu, T., 2007. Inclusion of solar reflectance and thermal emittance prescriptive requirements for residential roofs in Title 24. Lawrence Berkeley National Laboratory Report, LBNL-60271 (draft), Berkeley, CA. Online at

http://energy.ca.gov/title24/2008standards/documents/2006-05-18 workshop/2006-05-17 RESIDENTIAL ROOFS.PDF 
Table 1. Solar reflectances of tile assemblies and tile chips. Most tile assemblies were made of more than one component tile. The solar reflectances of assemblies were measured using E1918 and E1918A, while the solar reflectances of tile chips were measured via E903. The numbers in parentheses show the maximum difference for three solar reflectance measurements of each tile assembly.

\begin{tabular}{|c|c|c|c|c|c|c|c|}
\hline \multicolumn{5}{|c|}{ Tile Assembly Solar Reflectance } & \multicolumn{3}{|c|}{ Tile Chip Solar Reflectance } \\
\hline Code & Description and size & $\begin{array}{l}\text { Assembly } \\
\text { color/size }\end{array}$ & E1918 & E1918A & Component & Code & E903 \\
\hline CRRC01 & $\begin{array}{l}\text { Gladding McBean Terracotta } \\
3.3 \mathrm{~m} \text { x } 3.3 \mathrm{~m}\left(10^{\prime} \times 10^{\prime}\right)\end{array}$ & $\mathrm{U} / \mathrm{L}$ & $0.32(0.00)$ & $0.32(0.00)$ & \begin{tabular}{|l} 
Chip 01a \\
Chip 01b
\end{tabular} & $\begin{array}{l}\text { CRRC01A } \\
\text { CRRC01B }\end{array}$ & $\begin{array}{l}0.37 \\
0.35 \\
\end{array}$ \\
\hline CRRC02 & $\begin{array}{l}\text { Gladding McBean \#8 Mix } \\
3.3 \mathrm{~m} \text { x } 3.3 \mathrm{~m}\left(10^{\prime} \text { x } 10^{\prime}\right)\end{array}$ & $\mathrm{M} / \mathrm{L}$ & $0.23(0.00)$ & $0.22(0.01)$ & $\begin{array}{l}\text { Chip 02a } \\
\text { Chip 02b } \\
\text { Chip 02c }\end{array}$ & $\begin{array}{l}\text { CRRC02A } \\
\text { CRRC02B } \\
\text { CRRC02C }\end{array}$ & $\begin{array}{l}0.17 \\
0.35 \\
0.19\end{array}$ \\
\hline CRRC03 & $\begin{array}{l}\text { US Tile Terracotta } \\
3.3 \mathrm{~m} \text { x } 3.3 \mathrm{~m}\left(10^{\prime} \times 10^{\prime}\right)\end{array}$ & $\mathrm{U} / \mathrm{L}$ & $0.32(0.00)$ & $0.30(0.01)$ & \begin{tabular}{|l|} 
Chip 03a \\
Chip 03b \\
\end{tabular} & \begin{tabular}{|l|} 
CRRC03A \\
CRRC03B \\
\end{tabular} & $\begin{array}{l}0.31 \\
0.31 \\
\end{array}$ \\
\hline CRRC04 & $\begin{array}{l}\text { US Tile El Camino } \\
3.3 \mathrm{~m} \text { x } 3.3 \mathrm{~m}\left(10^{\prime} \text { x } 10^{\prime}\right)\end{array}$ & $\mathrm{M} / \mathrm{L}$ & $0.25(0.00)$ & $0.22(0.01)$ & $\begin{array}{l}\text { Chip 04a } \\
\text { Chip 04b } \\
\text { Chip 04c } \\
\text { Chip 04d } \\
\text { Chip 04e } \\
\text { Chip 04f** } \\
\end{array}$ & $\begin{array}{l}\text { CRRC04A } \\
\text { CRRC04B } \\
\text { CRRC04C } \\
\text { CRRC04D } \\
\text { CRRC04E } \\
\text { CRRC04F } \\
\end{array}$ & $\begin{array}{l}0.32 \\
0.10 \\
0.31 \\
0.17 \\
0.17 \\
0.10 \\
\end{array}$ \\
\hline CRRC05 & $\begin{array}{l}\text { MCA Adobe White } \\
3.3 \mathrm{~m} \text { x } 3.3 \mathrm{~m}\left(10^{\prime} \times 10^{\prime}\right)\end{array}$ & $\mathrm{U} / \mathrm{L}$ & $0.50(0.00)$ & $0.49(0.01)$ & Chip 05a & CRRC05A & 0.55 \\
\hline CRRC06 & $\begin{array}{l}\text { MCA Adobe Black } \\
3.3 \mathrm{~m} \times 3.3 \mathrm{~m}\left(10^{\prime} \times 10^{\prime}\right) \\
\end{array}$ & $\mathrm{U} / \mathrm{L}$ & $0.10(0.00)$ & $0.09(0.00)$ & Chip 06a & CRRC06A & 0.10 \\
\hline CRRC07 & $\begin{array}{l}\text { Westile Gray Hawk } \\
2.1 \mathrm{~m} \times 1.7 \mathrm{~m}\left(7.2^{\prime} \times 5.5^{\prime}\right)\end{array}$ & $\mathrm{M} / \mathrm{S}$ & $0.33(0.00)^{\dagger}$ & $0.37(0.01)$ & \begin{tabular}{|l|} 
Chip 07a \\
Chip 07b \\
Chip 07c \\
\end{tabular} & $\begin{array}{l}\text { CRRC07A } \\
\text { CRRC07B } \\
\text { CRRC07C }\end{array}$ & $\begin{array}{l}0.38 \\
0.32 \\
0.37 \\
\end{array}$ \\
\hline CRRC08 & $\begin{array}{l}\text { Westile Paloma } \\
2.1 \mathrm{~m} \times 1.6 \mathrm{~m}(7.2 \times 5.2)\end{array}$ & $\mathrm{M} / \mathrm{S}$ & $0.29(0.01)^{\dagger}$ & $0.28(0.01)$ & $\begin{array}{l}\text { Chip 08a } \\
\text { Chip 08b } \\
\text { Chip 08c } \\
\text { Chip 08d }\end{array}$ & $\begin{array}{l}\text { CRRC08A } \\
\text { CRRC08B } \\
\text { CRRC08C } \\
\text { CRRC08D }\end{array}$ & $\begin{array}{l}0.27 \\
0.42 \\
0.26 \\
0.35\end{array}$ \\
\hline CRRC09 & $\begin{array}{l}\text { MonierLifetile Desert Sage } \\
3.3 \mathrm{~m} \text { x } 3.3 \text { m (10' x 10') }\end{array}$ & $\mathrm{M} / \mathrm{L}$ & $0.19(0.00)$ & $0.19(0.01)$ & $\begin{array}{l}\text { Chip 09a* } \\
\text { Chip 09b } \\
\text { Chip 09c } \\
\text { Chip 09d* }\end{array}$ & $\begin{array}{l}\text { CRRC09A } \\
\text { CRRC09B } \\
\text { CRRC09C } \\
\text { CRRC09D }\end{array}$ & $\begin{array}{l}0.16 \\
0.20 \\
0.16 \\
0.17\end{array}$ \\
\hline CRRC10 & $\begin{array}{l}\text { Hanson Integrated Color } \\
3.3 \mathrm{~m} \text { x } 3.3 \mathrm{~m}\left(10^{\prime} \times 10^{\prime}\right)\end{array}$ & $\mathrm{M} / \mathrm{L}$ & $0.14(0.00)$ & $0.14(0.01)$ & $\begin{array}{l}\text { Chip } 10 a^{*} \\
\text { Chip } 10 b^{* *}\end{array}$ & \begin{tabular}{|l|} 
CRRC10A \\
CRRC10B \\
\end{tabular} & $\begin{array}{l}0.15 \\
0.11 \\
\end{array}$ \\
\hline CRRC11 & $\begin{array}{l}\text { Hanson Slurry } \\
3.3 \mathrm{~m} \text { x } 3.3 \mathrm{~m}\left(10^{\prime} \times 10^{\prime}\right)\end{array}$ & $\mathrm{M} / \mathrm{L}$ & $0.36(0.00)$ & $0.38(0.02)$ & $\begin{array}{l}\text { Chip 11a } \\
\text { Chip 11b } \\
\text { Chip 11c }\end{array}$ & \begin{tabular}{|l|} 
CRRC11A \\
CRRC11B \\
CRRC11C \\
\end{tabular} & \begin{tabular}{|l|}
0.49 \\
0.34 \\
0.27 \\
\end{tabular} \\
\hline CRRC12 & $\begin{array}{l}\text { Westile Pacific } \\
1.8 \mathrm{~m} \times 1.8 \mathrm{~m}\left(6^{\prime} \times 6^{\prime}\right)\end{array}$ & $\mathrm{M} / \mathrm{S}$ & $0.38(0.00)^{\dagger}$ & $0.43(0.01)$ & $\begin{array}{l}\text { Chip 12a* } \\
\text { Chip 12b* } \\
\text { Chip 12c* }\end{array}$ & \begin{tabular}{|l|} 
CRRC12A \\
CRRC12B \\
CRRC12C \\
\end{tabular} & \begin{tabular}{|l|}
0.49 \\
0.49 \\
0.48 \\
\end{tabular} \\
\hline CRRC13 & $\begin{array}{l}\text { Westile Gray Hawk Slurry } \\
1.5 \mathrm{~m} \text { x } 2.2 \mathrm{~m}\left(5^{\prime} \times 7.2^{\prime}\right) \\
\end{array}$ & $\mathrm{M} / \mathrm{S}$ & $0.32(0.01)^{\dagger}$ & $0.34(0.02)$ & \begin{tabular}{|l|} 
Chip 13a \\
Chip 13b
\end{tabular} & $\begin{array}{l}\text { CRRC13A } \\
\text { CRRC13B }\end{array}$ & $\begin{array}{l}0.37 \\
0.39 \\
\end{array}$ \\
\hline CRRC14 & $\begin{array}{l}\text { MonierLifetile Rio Grande } \\
3.3 \text { m x } 3.3 \text { m (10' x 10') }\end{array}$ & $\mathrm{M} / \mathrm{L}$ & $0.20(0.00)$ & $0.22(0.01)$ & $\begin{array}{l}\text { Chip 14a } \\
\text { Chip 14b } \\
\text { Chip 14c }\end{array}$ & $\begin{array}{l}\text { CRRC14A } \\
\text { CRRC14B } \\
\text { CRRC14C }\end{array}$ & $\begin{array}{l}0.24 \\
0.24 \\
0.24 \\
\end{array}$ \\
\hline
\end{tabular}

Notes: E1918 requires a sample size of at least $3 \mathrm{~m} \mathrm{x} \mathrm{3m} \mathrm{(about} \mathrm{10'} \mathrm{by} \mathrm{10').} \mathrm{E1918} \mathrm{measurements} \mathrm{for}$ samples CRRC07, CRRC08, CRRC12, and CRRC13 are subject to significant errors because of their smaller size. For these samples, E1918A results are more reliable. U: Unicolor; M: Multicolor; L: Small assembly; L: Large assembly.

* Slight visual variation between the color of the 'tile chip' and the actual tile used in the tile assembly.

** Significant visual variation between the color of the 'tile chip' and the actual tile used in the tile assembly.

† The solar reflectance measured by E1918 characterizes both the small assembly and its surroundings, while the E1918A measurement characterized only the sample area. 


\section{APPENDIX A \\ E-1918A Procedure \\ (NOTE: THIS IS NOT AN ASTM STANDARD)}

This pyranometer-based method for the measurement of solar reflectance (hereafter, "E1918A") permits the measurement of the solar reflectance of a small "target" area of interest. The solar irradiance (power per unit area; hereafter, simply "irradiance") incident on the sensor of a horizontal, downwardfacing pyranometer is a weighted average of the sunlight reflected by the target area and that reflected by its surroundings (see Figure A1). E1918A determines the reflectance of a target area from three consecutive measurements of reflected sunlight. In the first configuration, denoted by subscript 1 , the target area is exactly covered by a thin, solar-opaque white surface (hereafter, "white mask"). In the second configuration, denoted by subscript 2 , the target area is exactly covered by a thin, solar-opaque black surface (hereafter, "black mask"). In the third configuration, denoted by subscript 3 , the target area is uncovered. The E1918A reflectance of the target area is then determined from the following equation:

$$
R_{\mathrm{t}}=R_{\mathrm{b}}+\frac{I_{3}-I_{2}}{I_{1}-I_{2}}\left(R_{w}-R_{\mathrm{b}}\right) \quad \text { EQ A1 }
$$

where

$R_{\mathrm{t}}$ is the calculated solar reflectance of the target area,

$R_{\mathrm{b}}$ and $R_{\mathrm{w}}$ are the solar reflectances of the solar-opaque black and solar-opaque white masks measured via ASTM E903, and

$I_{1}, I_{2}$, and $I_{3}$ are irradiances incident on the pyranometer sensor in configurations 1,2 , and 3 .

As in ASTM Standard E1918, a pyranometer on a $1.5 \mathrm{~m}$ arm is extended over the center of the target area at a height of $0.5 \mathrm{~m}$ (Figure A1). The pyranometer (always horizontal) is faced upward to measure global horizontal insolation; faced downward to measure the sunlight reflected in each of the three configurations; and then faced upward to re-measure insolation.

\section{Procedure}

Align the stand such that the arm points toward the sun (the observer shall stand such that his shadow falls at least $2 \mathrm{~m}$ away from the center of the target area). There shall be no moving shadow within $2 \mathrm{~m}$ of the center of the target area other than the minimal shadow cast by the pyranometer and its stand. The pyranometer shall be parallel to the surface where measurement is conducted.

1 Position the pyranometer over the center of the target area.

2 Obscure the target area with the black mask, and then obscure the black mask with the white mask. Note the white mask must exactly cover the black mask.

3 Face the pyranometer upward to measure incoming horizontal global solar irradiance $\left(\mathrm{I}_{\mathrm{H}}\right)$. Check the measured incoming radiation against standard solar tables.

4 Face the pyranometer downward. First, measure the reflected solar irradiance $\left(\mathrm{I}_{1}\right)$ incident on the pyranometer sensor in configuration 1 (target exactly covered by opaque white mask). Next, measure the reflected solar irradiance $\left(\mathrm{I}_{2}\right)$ incident on the pyranometer sensor in configuration 2 (target exactly covered by opaque black mask). Finally, measure the reflected solar irradiance $\left(\mathrm{I}_{3}\right)$ incident on the pyranometer sensor in configuration 3 (target uncovered).

5 Face the pyranometer upward to re-measure incoming solar radiation for the second time $\left(\mathrm{I}_{\mathrm{H}}\right)$. If $\left|\mathrm{I}^{\prime}{ }_{\mathrm{H}}-\mathrm{I}_{\mathrm{H}}\right|>20 \mathrm{Wm}^{-2}$, repeat steps 2 to 5 .

6 All five pyranometer measurements $\left(\mathrm{I}_{\mathrm{H}}, \mathrm{I}_{1}, \mathrm{I}_{2}, \mathrm{I}_{3}, \mathrm{I}_{\mathrm{H}}\right)$ shall be performed in a time interval not to exceed 10 minutes. For each measurement, allow 30 seconds for the pyranometer to stabilize.

7 Calculate the solar reflectance of the target area $\left(\mathrm{R}_{\mathrm{t}}\right)$ using Eq. A1. 
8 Repeat steps 2 to 7 two more times to obtain a total of three values of $R_{t}$.

9 If the range of the three values of $R_{t}$ exceeds 0.02 [i.e., $\max \left(R_{t}\right)-\min \left(R_{t}\right)>0.02$ ], repeat steps 2-8.

\section{Figure captions}

Figure A1. A schematic of the pyranometer, pyranometer support, and masked target area.

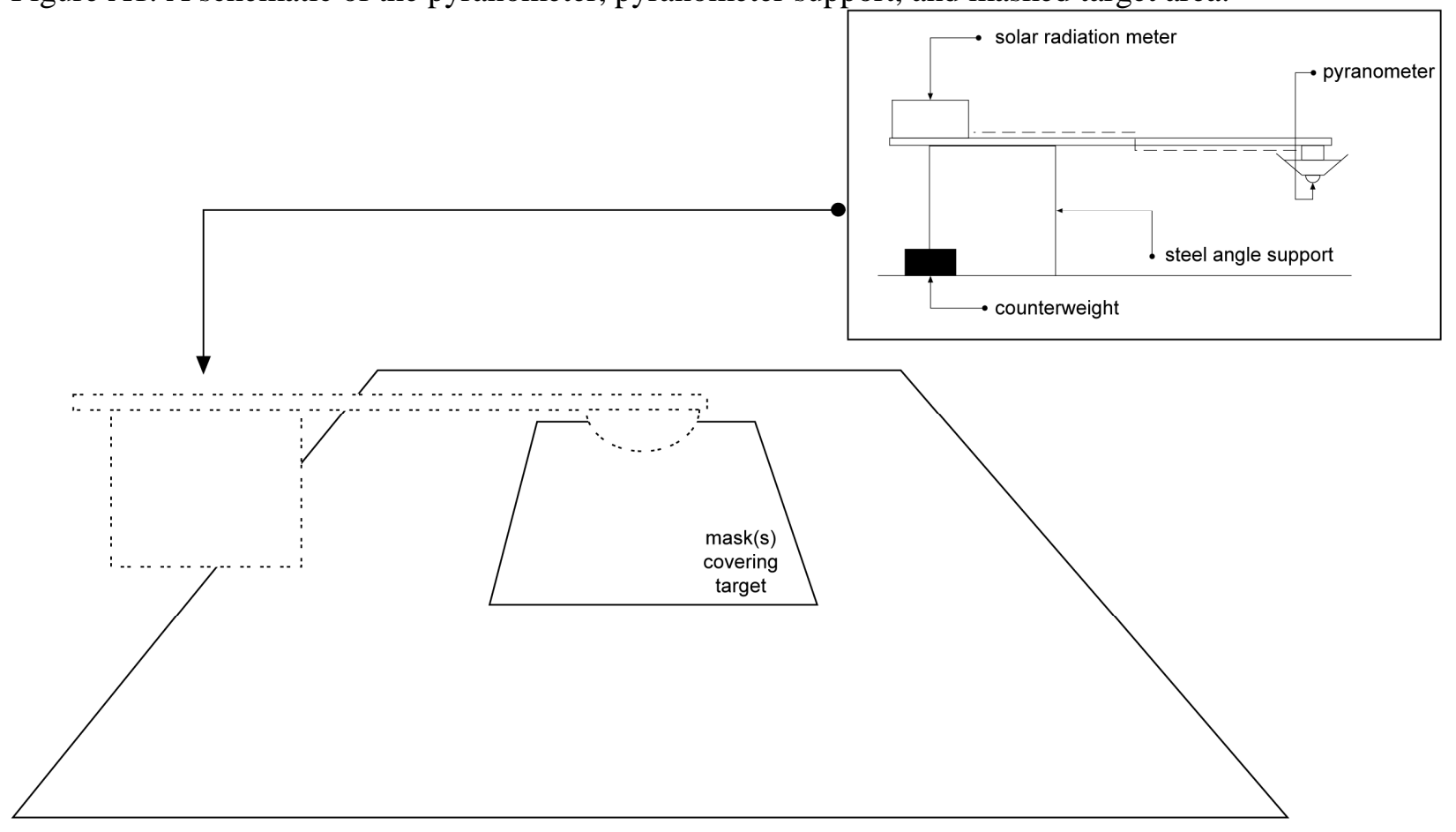

